\title{
Practica deporte, vive sano
}

Practice sports, live healthy

\author{
Geraldine Campos-Díaz ${ }^{1, a}$, Mario Fernández-Infantes ${ }^{1, a}$, \\ Manuel Castillo-Rimarachín ${ }^{1, a}$, Jorge Fernández-Mogollón ${ }^{2, b}$ \\ ${ }^{1}$ Escuela de Medicina Humana, Facultad de Medicina, Universidad Santo Toribio de Mogrovejo, Chiclayo, Perú. \\ 2 Epidemiólogo Clínico, Hospital Almanzor Aguinaga Asenjo. EsSalud - Lambayeque, Perú. \\ ${ }^{a}$ Estudiante de Medicina; ${ }^{b}$ Docente de Universidad Católica Santo Toribio de Mogrovejo.
}

An Fac med. 2015;76(1):79-80 / doi:10.15381/anales.v76i1.11080

Señor Editor:

La falta de actividad física y la inadecuada alimentación son un problema de salud pública cada vez más frecuente a nivel mundial ${ }^{(1)}$; esto lo podemos ver reflejado en la población con sobrepeso y obesidad que está aumentando con los años. Esta problemática se ha ido incrementando debido a factores como el desarrollo económico, el desarrollo tecnológico y social de los países que llevan a su población a tener una vida sedentaria. El sedentarismo está asociado a estos problemas que perjudican la salud de las personas, así como a enfermedades crónicas no transmisibles ${ }^{(2)}$.

El Perú no está ajeno a este problema, registrando cifras altas de sobrepeso y obesidad en niños menores de cinco años ${ }^{(3)}$. La población afectada son los niños y adolescentes que cursan la etapa escolar, que no tienen como hábito el practicar deportes y que no se alimentan adecuadamente. En tres colegios de Chiclayo se determinó que la prevalencia de obesidad en niños de siete a nueve años es $16,3 \%$ y de sobrepeso $22,1 \%{ }^{(4)}$. También se estima que los niños y adolescentes que son obesos en la actualidad seguirán siendo obesos en el futuro; esto se debe a que los hábitos alimenticios y la actividad física se construyen durante la infancia y adolescencia.

Tomando en cuenta este problema de salud pública, el Estado Peruano promulgó en mayo de 2013 la "Ley de la promoción de alimentación saludable para niños, niñas y adolescentes" (5), con la finalidad de brindar una alimentación adecuada a los niños en etapa escolar, con la implementación de alimentos saludables en los kioscos y fomentando la actividad física. Esta ley pretende disminuir el riesgo de que los niños lleguen a tener sobrepeso o ser obesos, basándose principalmente en una adecuada alimentación y ejercicio físico.

El practicar deportes trae consigo múltiples beneficios para la salud, como prevenir la obesidad, mejorar la agilidad, potenciar los reflejos, aumentar la velocidad y reforzar la resistencia física. También favorece que los niños y adolescentes no se inicien en el tabaquismo; les enseña a aceptar las reglas, disminuyendo así la tendencia a desarrollar actitudes agresivas, valorando el compañerismo y estimulando su rendimiento académico ${ }^{(6)}$.

Otra manera de ejercitarnos es el 'transporte activo', que consiste en la decisión de caminar, manejar bicicleta al trasladarnos de un lugar al otro, siendo esta la manera más práctica y sostenible de aumentar la actividad física diariamente, logrando beneficios ambientales como la mejora de la calidad del aire, la disminución del tráfico vehicular y la reducción de emisiones de $\mathrm{CO} 2{ }^{(7)}$. La Organización mundial de la Salud (OMS) recomienda que los niños y jóvenes de 5 a 17 años inviertan como mínimo 60 minutos diarios en actividades físicas de intensidad moderada a vigorosa, y es necesario incorporar como mínimo tres veces por semana actividades vigorosas que refuercen, en particular, los músculos y huesos ${ }^{(8)}$.

La medida tomada por el Estado daría mejores resultados si también se fomentara la actividad física en los centros educativos, tanto nacionales como particulares a nivel nacional, logrando que los escolares practiquen deportes tres veces a la semana como asignatura en el plan curricular de estudios. Con esta medida los niños y adolescentes cultivarían desde temprana edad el hábito de practicar deportes, permitiéndoles mantenerse saludables y reduciendo el riesgo de que padezcan enfermedades en el futuro.

\section{REFERENCIAS BIBLIOGRÁFICAS}

1. Guía para incrementar los niveles de Actividad Física. Organización Mundial de la Salud. 2008. Disponible en: http://www.who.int/dietphysicalactivity/PAguide-2007-spanish.pdf?ua=1

2. Amigo H. Obesidad en el niño en América Latina: situación, criterios de diagnóstico y desafíos. Cad Saude Pública. 2003;19(Suppl 1):S163-70.

3. Popkin BM. An overview on the nutrition transition and its health implications: the Bellagio meeting. Public Health Nutr. 2002;5(1A):93-103.

4. Soto V. Prevalencia de obesidad en niños de siete a nueve años en tres colegios de la ciudad de Chiclayo. Rev Cuerpo Med Hosp Nac Almanzor Aguinaga Asenjo. 2011;4(1):8-11.

5. Ley de Promoción de la alimentación saludable para niño, niñas y adolescentes. Ley 30021/2013 de 17 de Mayo. Diario Oficial El Peruano, (25-10-14). 
6. Fundación Española del Corazón [Internet]* España: FEC [acceso 28 de Noviembre de 2014]. Beneficios de la práctica deportiva para niños [aproximadamente 2 pantallas]. Disponible en: http://www.fundaciondelcorazon.com/ejercicio/ para-ninos/988-beneficios-de-la-practica-deportiva-para-ninos.html

7. Global Advocacy Council for Physical Activity, International Society for Physical Activity and Health. La Carta de Toronto para la Actividad Física: Un Ilamado Global para la Acción [Internet]. Inglate- rra: International Society for Physical Activity and Health; 2010 [acceso: 20 de Mayo de 2010; 28 de Noviembre de 2014]. Disponible en: http://activate. gob.mx/Documentos/Carta\%20de\%20Toronto\%20 para $\% 20$ la\%20Actividad\%20Fisica.pdf

8. OMS. Recomendaciones mundiales sobre la actividad física para la salud [Internet].Ginebra: who.int; [acceso 28 de noviembre de 2014]. Disponible en: http://www.who.int/dietphysicalactivity/ factsheet_recommendations/es/
Carta recibida el 3 de diciembre de 2014.

Conflictos de interés:

Los autores declaran no existir conflictos de interés en esta Carta al Editor.

Correspondencia:

Campos Díaz Geraldine Anabella

Email: geraldine-anabella@hotmail.com 